\title{
Application of 16s rDNA Sequencing in the Analysis of Pathogenic Bacteria in Sputum of Severe Bacterial Pneumonia
}

\author{
Jun Zheng1, Juan Zhu1, Bin Chen1', Lingxiu Chen'1, Tian Gao', Xinping Chen², Tao Huang2* \\ ${ }^{1}$ The Fourth People's Hospital of Haikou, Haikou, China \\ ${ }^{2}$ Hainan General Hospital, Haikou, China \\ Email: ^g2002m@163.com
}

How to cite this paper: Zheng, J., Zhu, J., Chen, B., Chen, L. X., Gao, T., Chen, X. P., \& Huang, T. (2021) Application of 16s rDNA Sequencing in the Analysis of Pathogenic Bacteria in Sputum of Severe Bacterial Pneumonia. Advances in Microbiology, 11, 109-116.

https://doi.org/10.4236/aim.2021.112008

Received: January 23, 2021

Accepted: February 21, 2021

Published: February 24, 2021

Copyright $\odot 2021$ by author(s) and Scientific Research Publishing Inc. This work is licensed under the Creative Commons Attribution International License (CC BY 4.0).

http://creativecommons.org/licenses/by/4.0/

\begin{abstract}
Objective: 120 patients with severe pneumonia who were kept in the comprehensive ICU of our hospital in 2018 were selected, and 16s rDNA sequencing was performed to analyze the composition of pathogenic bacteria in the sputum of severe pneumonia. Methods: The sputum samples of patients with severe bacterial pneumonia were collected, and the diversity of pathogens in the samples was analyzed by polymerase chain reaction (PCR) amplification and high-throughput sequencing (16s rDNA PCR-DGGE). Results: Sequence showed that sputum samples contained a relatively large number of species, and there were many species that were not detected by sequencing. The dominant bacteria were Streptococcus, Sphingomonas, Corynebacterium, Denatobacteria, Aquobacteria, Acinetobacteria, Prevotella, Klebsiella, Pseudomonas, etc. Conclusion: Bacteria caused by sputum of severe bacterial pneumonia are complex and diverse, which provides new methods and ideas for individualized treatment of patients with severe pneumonia.
\end{abstract}

\section{Keywords}

Bacterial Severe Pneumonia, Sputum, The Pathogenic Bacterium, 16s rDNA Sequencing

\section{Introduction}

The diagnosis of pathogenic bacteria in severe pneumonia is difficult and the prognosis is poor. Its outcome is closely related to bacterial pathogenicity and the timeliness and pertinence of antibiotic treatment, so early diagnosis is of great significance to the prognosis of patients [1]. The sputum samples of patients in the lower respiratory tract were collected by bronchoalveolar lavage, 
and the bacterial population in the sputum of patients with severe pneumonia was monitored and analyzed by 16 s rDNA PCR-DGGE technology, so as to explore the differences of bacterial species in patients with different degrees of severe pneumonia, and provide an important index reference for the diagnosis, precise treatment and prognosis of patients [2]. In this paper, the composition of bacteria in the respiratory tract of patients with bacterial infection pneumonia was prospectively studied by using the above methods, so as to understand the characteristics and interrelationship of bacteria in the respiratory tract and better detect the pathogenic bacteria. The 16s rDNA PCR-DGGE technology was used to identify and classify the bacteria in the sputum of pneumonia, and a new method of etiological diagnosis was explored [3] [4] [5] [6].

\section{Materials and Methods}

\subsection{Subjects and Sample Collection}

A total of 120 patients with severe pneumonia (10 normal controls) who were hospitalized in the comprehensive ICU of the Fourth People's Hospital of Haikou City and Hainan People's Hospital from January 2018 to December 2018 were selected as subjects. This study was approved by the Medical Ethics Committee of the Fourth People's Hospital of Haikou City, and the patients signed the informed consent.

Inclusion criteria: chest pain, dyspnea and other symptoms. The alveolar lavage fluid was positive. Age $\leq 50$ years old; Patients signed informed consent. Exclusion criteria: those who could not be tested with fiberoptic bronchoscopy; Combined with respiratory or heart failure; Patients with other serious infectious diseases; Patients with other pulmonary diseases; Complicated with systemic diseases; Complicated with heart, liver, kidney and other important organ dysfunction; No previous history of mental illness.

Sample collection: The sputum samples of the lower respiratory tract were collected by bronchoalveolar lavage. The lavage site was selected in the lung segment where the CT showed the heaviest inflammatory exudation. If the tight wedge at the top of the bronchoscope or the subsegmental bronchial opening cannot be absorbed due to the viscous sputum, $1-2 \mathrm{~mL}$ of normal saline should be quickly injected through the silicone tube through the re-biopsy hole. Each time 25 - $50 \mathrm{ml}$ of lavage fluid was recovered by suction of negative pressure into a sterile sputum collector, and 2 tubes of $2 \mathrm{ml}$ each were collected at the same time. One tube was immediately sent to the bacteria laboratory for bacterial and fungal culture, and the other tube was immediately stored in the refrigerator at $-80^{\circ} \mathrm{C}$ for later intensive extraction of bacterial genomic DNA for sequencing analysis.

\subsection{Methods}

\subsubsection{Bacterial Culture}

The sputum oscillating liquid was prepared and inoculated with Columbia blood 
plate and Haemophilus influenzae isolation plate, respectively, and cultured at $37^{\circ} \mathrm{C}$ for $18-48 \mathrm{~h}$. The positive bacterial colonies were stained by Gram, and the bacterial species were identified by MicroscanWalkAway 40 (Siemens) automatic bacterial identification/drug sensitivity tester. Another sputum sample from a patient whose sputum was cultured with pathogenic bacteria was performed as follows.

\subsubsection{Main Reagents}

DNEasy Bloodand Tissus $\mu \mathrm{E}$ Kit (Qiagen, Germany); PCR amplification kit, Dream Taq PCR Master Mix (Fermentas, Canada) [7]. The sputum samples should be centrifuged at $4^{\circ} \mathrm{C}$ for $10,000 \mathrm{r} / \mathrm{min}$ for $1 \mathrm{~min}$, and the supernatant should be discarded. Then add $2 \mathrm{~mL}$ of sterilized saline to the precipitate and mix. Repeat the centrifugation operation as above. The above cleaning needs to be repeated twice. Take the sediment and extract the bacterial DNA according to the instructions of the microbacteria extraction kit.

\subsubsection{PCR}

The upstream primer sequence was 5'-CGC CCG GGG CGC GCC CCG GGC GCA GGG G CCTACG GGA GGC AGC Ag-3, and the downstream primer sequence was 5'-ATT ACC GCG GCT GCT GCT GG-3. The extracted bacterial DNA was amplified using a gradient PCR device (Eppendoff) [8]. 16S RDNAPCR procedure: pre-denaturation at $94^{\circ} \mathrm{C}$ for $5 \mathrm{~min}$; The denaturation at $94^{\circ} \mathrm{C}$ for 30 s, annealing at $61^{\circ} \mathrm{C}-56^{\circ} \mathrm{C}, 0.5^{\circ} \mathrm{C}$ for each cycle, $72^{\circ} \mathrm{C}$ for $1 \mathrm{~min}$, a total of 10 cycles; It was denatured at $94^{\circ} \mathrm{C}$ for $30 \mathrm{~s}$, annealed at $56^{\circ} \mathrm{C}$ for $30 \mathrm{~s}$, and extended at $72^{\circ} \mathrm{C}$ for $1 \mathrm{~min}$. A total of 25 cycles; it was extended at $72^{\circ} \mathrm{C}$ for $7 \mathrm{~min}$. The detection method of 16s rDNA PCR amplification product was to take $5 \mathrm{uL}$ of the amplification product and add it into the preprepared 2\% agarose gel for electrophoresis, the voltage was $110 \mathrm{~V}$, the time was $30 \mathrm{~min}$. Standard DNA is DL500 (Takara Company) [9]. After electrophoresis, the agarose gel was placed on the gel imager to detect and record the results. The number of nucleic acid sequence of the target band was about $195 \mathrm{bp}$. The remaining amplification products were stored at $-20^{\circ} \mathrm{C}$.

\subsubsection{Recovery and Amplification of DGG and Bacterial DNA}

The deCODE system (Bio. Rad Corporation) was used for DGGE. $25 \mathrm{uL}$ amplified products were absorbed and added to preformulated $8 \%$ polyacrylamide gel [10]. The denaturation gradient was $35 \%-65 \%, 60^{\circ} \mathrm{C}, 110 \mathrm{~V}$ electrophoresis for $6 \mathrm{~h}$. After the electrophoresis was completed, the gel was stained with SYBR Green I (Tektronix), and imaging was performed with a gel imager and recorded. All the strips in the DGGE gel were cut off, washed twice with $500 \mathrm{uL}$ sterilized DDH20, mashed the gel, added $30 \mathrm{uL}$ DDH20 with nuclease removal, and then isolated out at $4^{\circ} \mathrm{C}$ overnight. Supernatant (containing target DNA) was absorbed and amplified with upstream and downstream primers without "GC" cap. The reaction system and conditions were the same as 1. 2. 
3. $5 \mathrm{uL}$ of the amplified product was added into the preprepared $2 \%$ agarose gel for electrophoresis at $110 \mathrm{~V}$ and $20 \mathrm{~min}$. Standard DNA is DL500. After the electrophoresis, the AGAR was placed on the gel imager for detection and the results were recorded. DNA in the bands was recovered and purified by Agarose Gel DNA Purification Kit Ver2.0. TAKARA Company, and stored at $-20^{\circ} \mathrm{C}[11]$.

\subsubsection{Cloning and Sequencing}

The amplified product was transferred into the plasmid using pMDL8-T Vector system (Takara Company), and then the cloned product was transferred into Escherichia coli DH50T competent cells (Tiangen Biochemical Technology Co., Ltd.). The cloned single colonies were selected and inoculated into a plate containing ampicillin (LB/AMP). The bacteria were shaken overnight at $37^{\circ} \mathrm{C}$ at 200 $\mathrm{r} / \mathrm{min}$, and $2 \mathrm{~mL}$ of bacterial liquid was absorbed and sent to Shanghai Sangon Bioengineering Company for sequencing. Sequencing results in the national center for biotechnology information (NCBI) database for Blast ratio.

\subsection{Statistical Treatment}

SPSSL 7.0 statistical software was used for data analysis. Measurement data conforming to the normal distribution are expressed as $(\mathrm{x} \pm \mathrm{s})$. Independent sample $t$ test was used for comparison between two groups when variance was homogeneous, one-way analysis of variance was used for comparison between multiple groups, and LSD-t test was used for pair comparison. If the variance is not uniform and still does not meet the requirements of ANOVA after correction, non-parametric test will be used. Measurement data that do not conform to normal distribution are represented by $\mathrm{P}_{50}\left(\mathrm{P}_{25}-\mathrm{P}_{75}\right)$, and non-parametric test method is adopted. Pairwise comparison of several groups of enumeration data was performed after correction test level. $\mathrm{P}<0.05$ was considered statistically significant.

\section{The Results}

\subsection{Results of Sputum Specimen Culture}

There was no bacterial growth in 56 of 130 sputum samples. Normal flora was detected in 25 cases (including 10 normal controls). Fifty-nine pathogenic bacteria (including 38 Klebsiella pneumoniae, 16 Acinetobacter baumannii and 5 Pseudomonas aeruginosa) were detected. The detection rate of pathogenic bacteria was $45.2 \%$.

\subsection{Bacterial DNA Extraction, PCR and DGGE}

Thirty-five pre-stored sputum specimens corresponding to the samples of pathogenic bacteria were collected. Bacterial DNA was extracted, amplified and electrophoresis was performed, and then DGGE was performed. No target DNA was extracted from the negative control group (Figure 1). 


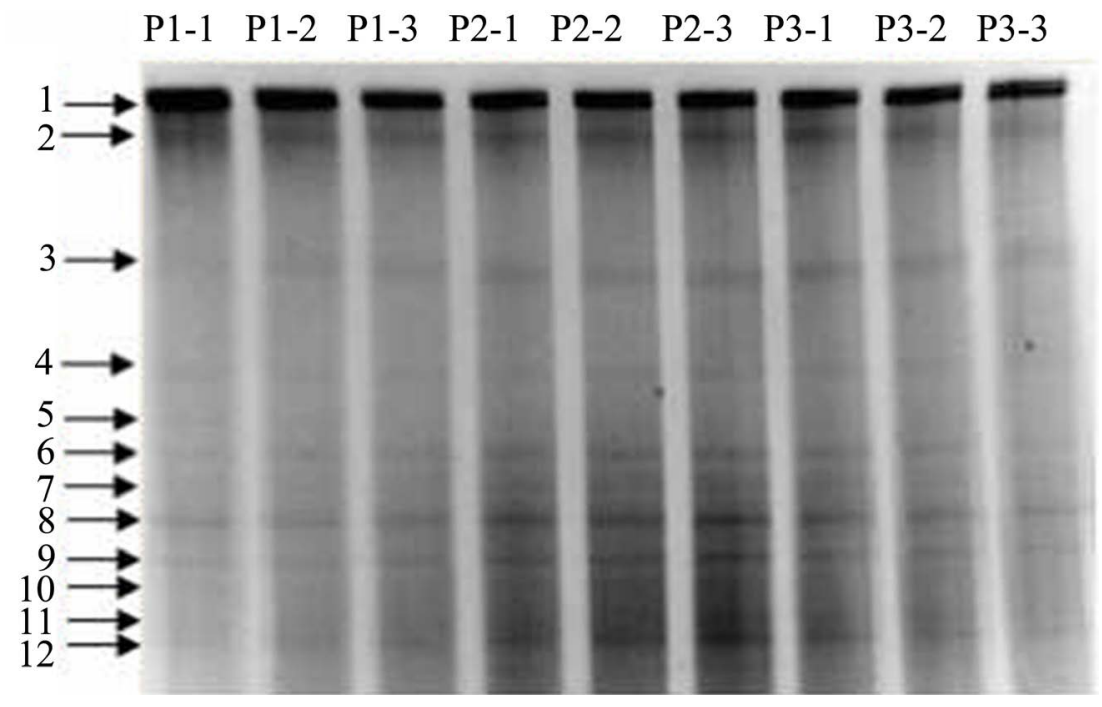

Figure 1. DGGE view of PCR product.

\subsection{Sequencing}

A total of 19 bacterial species were detected by DNA cloning and sequencing of each band after DGGE extraction. They are Photorhabdus, Serratia, Klebsiella, Staphylococcus, Acinetobacter, Streptococcus, Pelagibacter ubique, Pseudomonas, Pseudomonadaceae, Enterobacter sp, Bacillus Subtilis, Rothia, Nevskia, D. acidovorans, Stenotrophomonas and Dyella, and three genera of inculturable bacteria.

\subsection{Composition of Bacteria}

The composition and composition ratio of bacteria in sputum are shown in $\mathrm{Ta}$ ble 1. Table 1 shows that: 1) Comparison of bacterial species in upper and lower respiratory tract and composition ratio of each bacterial genus. The differences were statistically significant $(\mathrm{P}<0.05) ; 2)$ A total of 12 species of bacteria were detected in sputum. The number of bacteria genera detected in upper respiratory tract was more than that in lower respiratory tract, and the difference in the composition ratio of bacteria genera between upper and lower respiratory tracts was statistically significant $(\mathrm{P}<0.05) .3)$ Seven identical bacterial genera were detected in the upper and lower respiratory tracts, including Klebsiella, Achromobacter, Serratia, Acinetobacter, Streptococcus, Staphylococcus and Pelagobacter. The total composition ratio of common bacterial genera in the upper respiratory tract was $82.1 \%$, and that in the lower respiratory tract was $92.6 \%$.

\section{Discussion}

The 16s rDNA PCR-DGGE cloning and sequencing method was used to determine the bacteria in the respiratory tract of neonates with bacterial infection pneumonia. It was found that there were a lot of bacteria species detected in the upper and lower respiratory tracts. A total of 19 bacteria genera were detected in the upper respiratory tract and 13 bacteria genera in the lower respiratory tract. 
Table 1. Bacteria and composition ratio in sputum (\%).

\begin{tabular}{|c|c|c|}
\hline The serial number & Bacterial species & Detection of sputum (\%) \\
\hline 1 & Klebsiella & 23.4 \\
\hline 2 & Serratia & 41.5 \\
\hline 3 & Photorhabdus & 7.4 \\
\hline 4 & Streptococcus & 8.9 \\
\hline 5 & Acinetobacter & 6.2 \\
\hline 6 & Staphylococcus & 4.7 \\
\hline 7 & Pelagibacter ubique & 1.7 \\
\hline 8 & Pseudomonas & 0.0 \\
\hline 9 & Pseudomonadaceae & 0.0 \\
\hline 10 & Enterobacter $s p$ & 0.0 \\
\hline 11 & Bacillus subtilis & 0.0 \\
\hline 12 & Rothia & 0.0 \\
\hline 13 & Nevskia & 0.0 \\
\hline 14 & D.acidovorans & 0.0 \\
\hline 15 & Stenotrophomonas & 0.0 \\
\hline 16 & Dyella & 0.0 \\
\hline 17 & Bacteria that cannot be cultured A & 1.6 \\
\hline 18 & Bacteria that cannot be cultured B & 1.2 \\
\hline 19 & Bacteria that cannot be cultured C & 0.5 \\
\hline
\end{tabular}

Bacteria in the upper respiratory tract are more diverse than those in the lower respiratory tract. This may have to do with the fact that the pharynx is more exposed to the environment and less affected by antibiotics. In this study, the bacterial species of upper and lower respiratory tract and the composition ratio of each genus were compared. The difference was statistically significant $(\mathrm{P}<0.05)$. Therefore, it seems impossible to predict bacterial infection of the lower respiratory tract directly from the composition and variation of pharyngeal bacteria. Considering the indirect effect of pharyngeal flora on pneumonia, this is consistent with previous reports [12]. In this study, there were 7 common bacterial genera in the upper and lower respiratory tract, and the sequencing results of the same genus were consistent. Meanwhile, the bacterial composition of the common detected bacteria in the lower respiratory tract accounted for $92.6 \%$. It shows that the bacteria in the lower respiratory tract share a great deal of homology with the bacteria in the upper respiratory tract, and they mainly come from the upper respiratory tract. That is to say, the bacteria in the lower respiratory tract are still affected by the upper respiratory tract to a large extent. In this study, the pathogenic bacteria cultured in sputum were Klebsiella pneumoniae subspecies, Acinetobacter baumannii and Pseudomonas aeruginosa. These three bacteria belong to the genus Klebsiella, Acinetobacter and Pseudomonas, just the 
upper and lower respiratory tract of the common bacteria. In this study, 16s rDNA Acer genomic sequencing technology was applied to the etiological analysis of the sputum of severe pneumonia, and it was found that the pathogenic bacteria of severe pneumonia sputum were complex and rich in species, and a variety of multi-drug resistant strains were colonized in the sputum. Compared with common bacterial culture, the positive rate of pathogens detected by sequencing method is higher, with the cost of high-throughput sequencing technology gradually decreasing. This research group will make more use of this technique to reduce the experimental flow, increase the accuracy of sequencing and reduce information loss. By designing longer general primers to determine the species of bacteria, and improving the investigation of common bacterial strains and endemic bacteria in the upper and lower respiratory tract of bacterial infectious pneumonia in ICU ward, the clinical treatment can be better guided.

\section{Foundation Project}

Supported by Hainan Natural Science Foundation (Project No. 819MS143).

\section{Conflicts of Interest}

The authors declare no conflicts of interest regarding the publication of this paper.

\section{References}

[1] Cook, D. (2000) Ventilator Associated Pne $\mu$ monia: Perspectives on the Burden of Illness. Intensive Care Medicine, 26, 31-37. https://doi.org/10.1007/s001340051116

[2] Jumpstart Consortium Human Microbiome Project Data Generation Working Group. (2012) Evaluation of 16s rDNA-Based Community Profiling for Human Microbiome Research. PLOS ONE, 7, e39315. https://doi.org/10.1371/journal.pone.0039315

[3] Baker, G.C., Smith, J.J. and Cowan, D.A. (2003) Review and Re-Analysis of Domain-Specific 16S Primers. Journal of Microbiological Methods, 55, 541-555. https://doi.org/10.1016/j.mimet.2003.08.009

[4] Chakravorty, S., Helb, D., Burday, M., et al. (2007) A Detailed Analysis of 16S Ribosomal RNA Gene Segments for the Diagnosis of Pathogenic Bacteria. Journal of Microbiological Methods, 69, 330-339. https://doi.org/10.1016/j.mimet.2007.02.005

[5] Relman, D.A., Loutit, J.S., Schmidt, T.M., et al. (1990) The Agent of Bacillary Angiomatosis. An Approach to the Identification of Uncultured Pathogens. The New England Journal of Medicine, 323, 1573-1580. https://doi.org/10.1056/NEJM199012063232301

[6] Marín, M., Munoz, P., Sánchez, M., et al. (2007) Molecular Diagnosis of Infective Endocarditis by Real-Time Broadrange Polymerase Chain Reaction (PCR) and Sequencing Directly from Heart Valve Tissue. Medicine, 86, 195-202. https://doi.org/10.1097/MD.0b013e31811f44ec

[7] Helgason, E., Okstad, O.A., Caugant, D.A., et al. (2000) Bacillus anthracis, Bacillus cereus, and Bacillus thuringiensis-One Species on the Basis of Genetic Evidence. Applied and Environmental Microbiology, 66, 2627-2630. https://doi.org/10.1128/AEM.66.6.2627-2630.2000 
[8] Sacchi, C.T., Whitney, A.M., Mayer, L.W., et al. (2002) Sequencing of 16s rRNA Gene: A Rapid Tool for Identification of Bacillus anthracis. Emerging Infectious Diseases, 8, 1117-1123. https://doi.org/10.3201/eid0810.020391

[9] Horvat, R.T., El Atrouni, W., Hammoud, K., et al. (2011) Ribosomal RNA Sequence Analysis of Brucella Infection Misidentified as Ochrobactrum anthropi Infection. Journal of Clinical Microbiology, 49, 1165-1168. https://doi.org/10.1128/JCM.01131-10

[10] Woo, P.C., Lau, S.K., Teng, J.L., et al. (2008) Then and Now: Use of 16s rDNA Gene Sequencing for Bacterial Identification and Discovery of Novel Bacteria in Clinical Microbiology Laboratories. Clinical Microbiology and Infection, 14, 908-934. https://doi.org/10.1111/j.1469-0691.2008.02070.x

[11] Payne, S., Goss, C., Connett, J., et a1. (2010) Molecular Microbiological Characteri. Zation of Preterm Neonates at Risk of Bronchopulmonary Dysplasia. Pediatric Research, 67, 412-418. https://doi.org/10.1203/PDR.0b013e3181d026c3

[12] Benninger, M.B., Brook, I., Bernstein, J.M., et a1. (2011) Bacterial Interfefence in Upper Respiratory Tract Infections: A Systematic Review. American Journal of Rhinology \& Allergy, 25, 82-88. https://doi.org/10.2500/ajra.2011.25.3594 